\title{
STUDY OF OPERATIONAL CAPABILITIES OF CHEMICAL SOURCES OF ELECTRICITY INFLUENCED BY AMBIENT FACTORS
}

\author{
Galina IVANOVA \\ "Vasil Levski" National Military University, Veliko Tarnovo, Bulgaria \\ galina_h_ivanova@abv.bg
}

\begin{abstract}
This study focuses on the possibility of using chemical sources of electricity to power smallsized equipment with a short-term activity. Physical models of the suggested battery were used and their performance was studied according to the requirements for testing the effects of both changes in temperature and reduced atmospheric pressure. Qualitative methods were implemented to define the performance of the test specimens.
\end{abstract}

Keywords: batteries, alkaline silver, lithium

In order to conduct a comparative analysis, three types of electrochemical batteries were developed and constructed with the same type and size of their components. Due to the accessibility of the materials, the batteries were composed of alkaline /manganese-zinc/, silver and lithium systems. The proposed study is part of a larger research related to the operation of small-sized equipment with a short-term activity.

A batch of batteries was tested and the specimens were chosen randomly - alkaline -2 /two/ samples, silver -2 /two/ samples, and lithium $-2 /$ two/ samples with the objective of proving their efficiency after the conducted tests and after an extended period of inactivity.

1. Testing the effects of changes in temperature - BDS EN 60068-2-14:2009, Test N: Change of temperature Ambient conditions during the test:

Temperature: $(17.1 \pm 0.1){ }^{\circ} \mathrm{C}$;

Relative humidity: $(41 \pm 1.5) \%$.

Used climatic chambers: IF 3626; IF 3007; TBV 1000 [1].
The temperature of the tested specimens was stabilised at $(17.1 \pm 2){ }^{\circ} \mathrm{C}$ for 2 hours.

Testing conditions for one cycle:

The tested alkaline and silver batteries were put in a chamber (IF 3626) when the temperature in it reached the temperature of minus $(25 \pm 2){ }^{\circ} \mathrm{C}$. The duration of their stay in the chamber was 30 minutes. After that the tested specimens were moved to another chamber (TBV 1000) at a temperature of plus $(50 \pm 2){ }^{\circ} \mathrm{C}$ for 30 more minutes.

The time that the movement of the tested batteries from one chamber to the other took was $(1.2 \pm 0.1)$ minutes.

The total test time for one cycle was 1 hour and 2.4 minutes.

The total number of the conducted cycles was 5.

The voltage of the tested specimens was measured without load and under load (120 $\Omega$ for 10 seconds). The technological time needed was 10 minutes.

The data obtained are reported in table 1 . 
Table 1Measured voltage values during a conducted test on the effects of changes in temperature

\begin{tabular}{|l|c|c|}
\hline Battery № & $\begin{array}{c}\mathbf{t}_{1}=\mathbf{0 ~ s} \\
{[\mathbf{V}]}\end{array}$ & $\begin{array}{c}\mathbf{t}_{\mathbf{2}}=\mathbf{1 0} \mathbf{~ s} \\
{[\mathbf{V}]}\end{array}$ \\
\hline manganese-zinc (1.00004) & 12.500 & 8.8 \\
\hline manganese-zinc (1.00005) & 12.545 & 9.2 \\
\hline silver (2.00002) & 12.830 & 9.8 \\
\hline silver (2.00003) & 12.840 & 9.8 \\
\hline
\end{tabular}

Figure 1 depicts the change of the working voltage of the manganese-zinc and silver batteries under a load of $120 \Omega$ for a period of 10 seconds. The temperature interval was changed from minus $25{ }^{\circ} \mathrm{C}$ to plus $50{ }^{\circ} \mathrm{C}$.
The lithium batteries were not subjected to test in the above temperature interval as they had performed with very good results in previous tests.

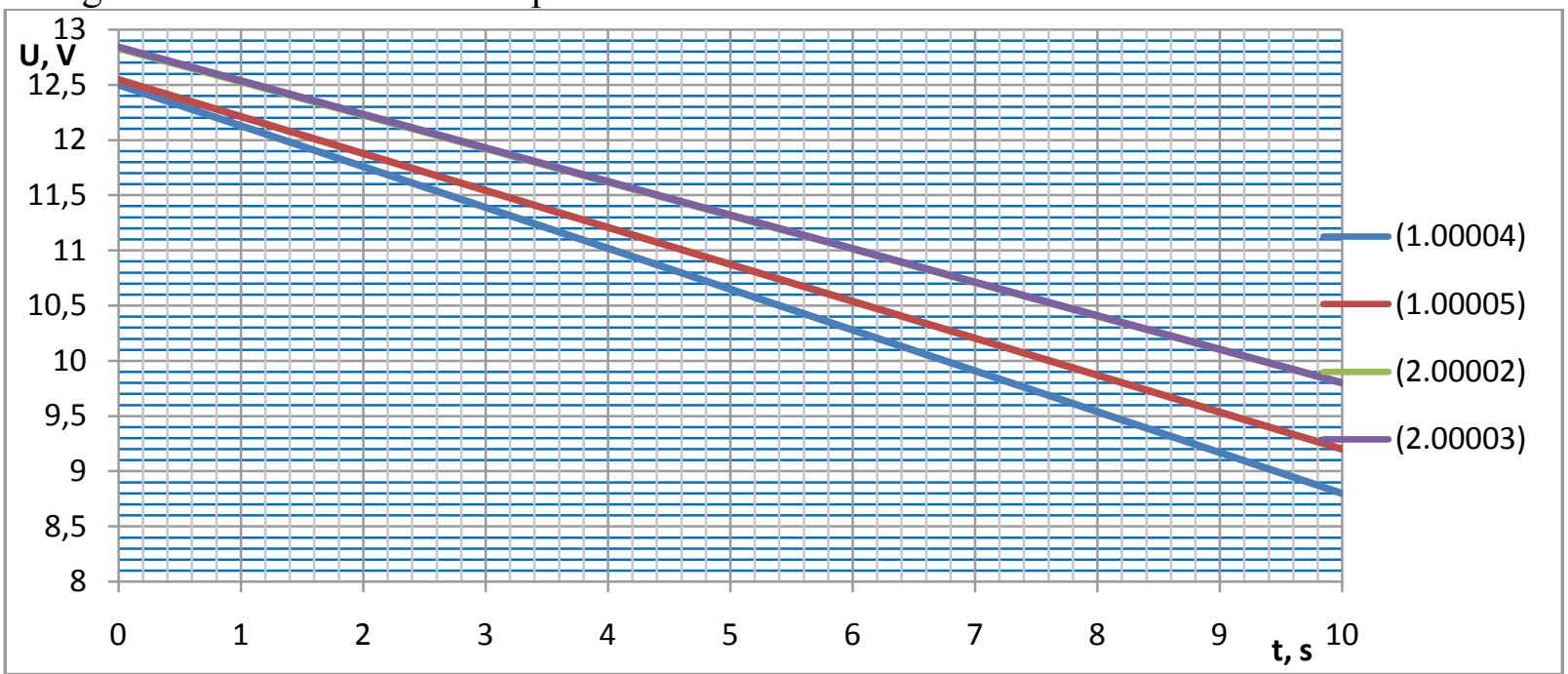

Figure 1: Graph of voltage values after conducting a test on the effects of changes in temperature

The tested lithium batteries were put in a chamber (IF 3007) when the temperature in it reached minus $(40 \pm 2){ }^{\circ} \mathrm{C}$ with a duration of the test 30 minutes. After that all tested batteries were moved to the second chamber (TBV 1000) at the temperature of $(50 \pm 2){ }^{\circ} \mathrm{C}-$ the duration of their stay in this chamber was 30 minutes.

The time that the movement of the tested batteries from one chamber to the other took was $1.2 \pm 0.1$ minutes.
The total test time for one cycle was 1 hour and 2.4 minutes.

The total number of the conducted cycles was 5 .

The voltage of the tested lithium batteries was measured without load and under load (120 $\Omega$ for $10 \mathrm{~s})$. The technological time needed was 10 minutes.

Table 2Measured voltage values of lithium batteries during a conducted test on the effects of changes

\begin{tabular}{|l|c|c|}
\hline Battery № & \multicolumn{2}{|c|}{ in temperature } \\
& $\begin{array}{c}\mathbf{t}_{1}=\mathbf{0 ~ s} \\
{[\mathbf{V}]}\end{array}$ & $\begin{array}{c}\mathbf{t}_{2}=\mathbf{1 0} \mathbf{~ s} \\
{[\mathbf{V}]}\end{array}$ \\
\hline lithium (3.00003V) & 12.992 & 10.6 \\
\hline lithium (3.00004S) & 12.948 & 10.4 \\
\hline
\end{tabular}




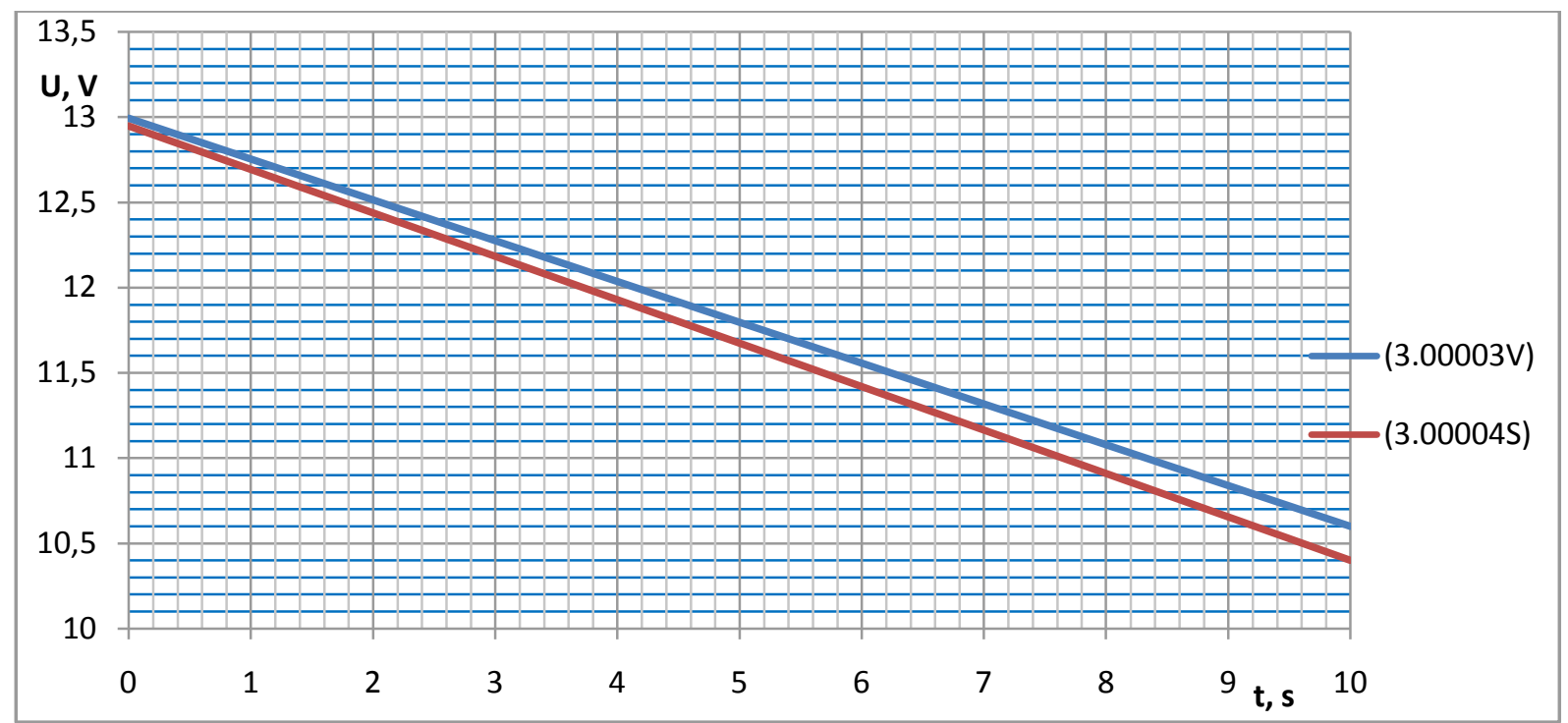

Figure 2 Graph of voltage values of lithium batteries after conducting a test on the effects of changes in temperature

2. Testing the effects of reduced atmospheric pressure - BDS EN 60068-2-

13:2003, Test M: Low air pressure

Ambient conditions during the test:

Temperature: $(17.3 \pm 0.1)^{\circ} \mathrm{C}$;

Relative humidity: $(52 \pm 1.5) \%$

Used climatic chambers: TBV 1000.
The tested batteries were put in the chamber when the temperature in it reached $(0 \pm 2)$ ${ }^{\circ} \mathrm{C}$. The pressure was reduced to $(19.20 \pm$ $0.31) \mathrm{kPa}$ (145 Torr) [2]. The duration of the stay was 40 minutes. The voltage values of the tested specimens were measured and the duration of the test was 10 minutes.

Table 3Measured voltage values of batteries without load during a conducted test on the effects of

\begin{tabular}{|l|c|c|}
\hline \multicolumn{3}{|c|}{ reduced atmospheric pressure } \\
\hline Battery № & $\begin{array}{c}\mathbf{t} \mathbf{1}=\mathbf{0} \text { s } \\
{[\mathbf{V}]}\end{array}$ & $\begin{array}{c}\mathbf{t} \mathbf{2}=\mathbf{1 0} \text { s } \\
{[\mathbf{V}]}\end{array}$ \\
\hline manganese-zinc (1.00004) & 12.500 & 12.467 \\
\hline manganese-zinc (1.00005) & 12.545 & 12.502 \\
\hline silver (2.00002) & 12.830 & 12.811 \\
\hline silver (2.00003) & 12.840 & 12.821 \\
\hline lithium (3.00003V) & 12.992 & 12.222 \\
\hline lithium (3.00004S) & 12.948 & 12.300 \\
\hline
\end{tabular}

Figure 3 depicts the change of the voltage of the tested batteries without load after a test was conducted on the effect of reduced atmospheric pressure. The alkaline and silver batteries did not demonstrate a substantial change of their indicators, but the voltage of the lithium batteries dropped down significantly. 


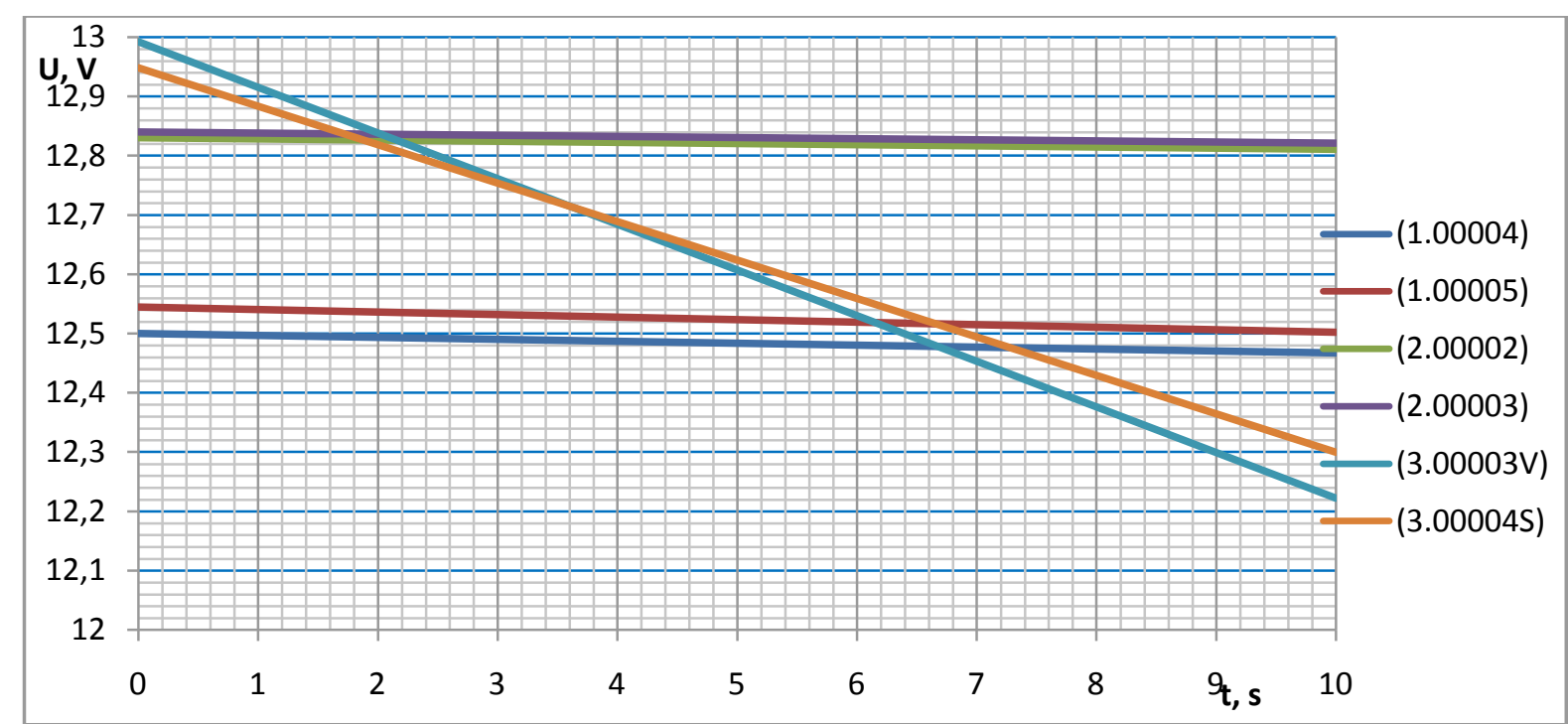

Figure 3 Graph of voltage values of batteries after conducting a test on the effects of reduced atmospheric pressure

An additional test under load was results are presented in table 4. performed with the lithium batteries, and its

Table 4Changes of the working voltage of lithium batteries after conducting a test at reduced

\begin{tabular}{|l|c|c|}
\hline Battery № & $\begin{array}{c}|c| \\
\text { t1 } \mathbf{0} \text {. s } \\
{[\mathrm{V}]}\end{array}$ & $\begin{array}{c}\mathbf{t}_{2}=\mathbf{1 0} \text { s } \\
{[\mathrm{V}]}\end{array}$ \\
\hline lithium (3.00003V) & 12.992 & 9.774 \\
\hline lithium (3.00004S) & 12.948 & 10.000 \\
\hline
\end{tabular}

Because of the demonstrated significant voltage change, the lithium batteries were subjected to the impact of a load of $120 \Omega$ for 10 seconds. The purpose of this experiment was to prove their efficiency in the conditions of reduced atmospheric pressure.

The voltage values of the lithium chemical sources of electricity were more than satisfactory and met the pre-set requirements.

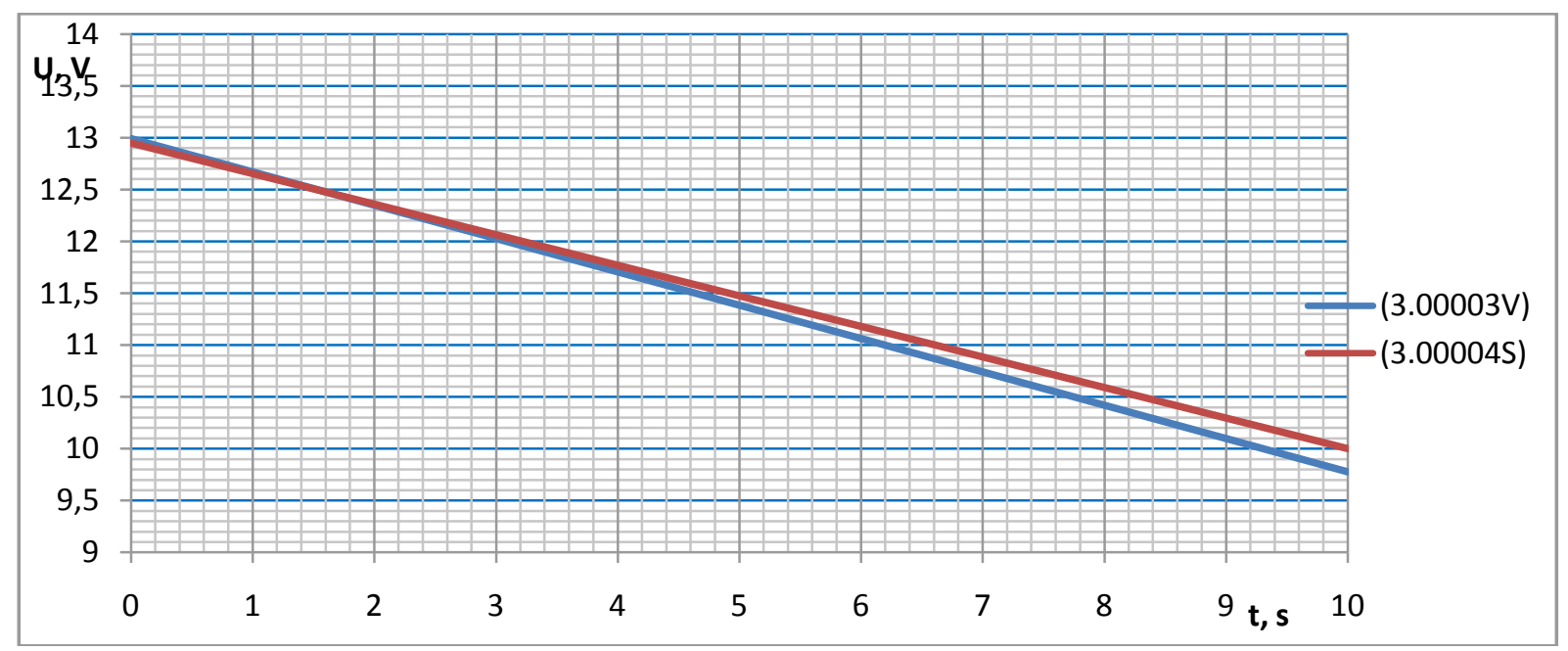

Figure 4 Graph of the operating voltage of lithium batteries under load after conducting a test at reduced atmospheric pressure 
The conducted tests proved the efficiency of the developed batteries, as well as the possibility for their application with a supply of over $6 \mathrm{~V}$ in accordance with the requirement for the final product for which they are intended.

\section{Conclusions}

The following conclusions could be made based on the conducted laboratory tests:

The tested batteries meet the set requirements for a power supply source of small-sized equipment with a working voltage of above $6 \mathrm{~V}$ measured after cyclic tests with temperature changes.

The examined manganese-zinc and silver electrochemical sources are useful in the temperature range from minus $30^{\circ} \mathrm{C}$ to plus $50^{\circ} \mathrm{C}$, and the lithium ones from minus $40^{\circ} \mathrm{C}$ to plus $50^{\circ} \mathrm{C}$.

The conducted test at reduced atmospheric pressure and the cyclic temperature test did not have a negative impact on the voltage of the lithium electrochemical systems.

\section{References}

[1] Testing the effects of changes in temperature - BDS EN 60068-2-14:2009, Test N: Change of temperature

[2] Testing the effects of reduced atmospheric pressure - BDS EN 60068-2-13:2003, Test M: Low air pressure 